\title{
LAS TÉCNICAS DE ANIMACIÓN Y LA ESTÉTICA DE LA IMAGEN EN LA REESCRITURA FÍLMICA DE LA LITERATURA FANTÁSTICA INFANTIL Y JUVENIL DIFUNDIDA EN ESPAÑA (1996-2019)
}

\author{
Animation Technigues and Image Aesthetics in the Rewriting for the Big \\ Screen of Fantastic Children and Youth Literature Broadcast in Spain \\ (1996-2019)
}

TECHNIQUES D'ANIMATION ET ESTHÉTIQUE DE L'IMAGE DANS LA RÉÉCRITURE FILMIQUE DE LA LITTÉRATURE FANTASTIQUE POUR L'ENFANCE ET LA JEUNESSE DIFFUSÉE EN ESPAGNE (1996-2019)

\section{TÉCNICAS DE ANIMAÇÃo E ESTÉTICA DA IMAGEM NA REESCRITA FílMICA DA LITERATURA FANTÁSTICA INFANTIL E JUVENIL DIFUNDIDA NA ESPANHA (1996-2019)}

\author{
Rocío García-Pedreira \\ Profesora Departamento de \\ Didácticas Aplicadas, LITER21, \\ Universidade de Santiago de Com- \\ postela, Santiago de Compostela, \\ España. \\ mariadelrocio.garcia.pedreira@usc.es \\ https://orcid. \\ org/0000-0002-5102-5078

\section{Sara Reis da Silva} \\ Profesora Departamento Estudos \\ Integrados de Literacia, Didáctica e \\ Supervisão, IE-CIEC, Universidade do \\ Minho, Minho, Portugal. \\ sara_silva@ie.uminho.pt \\ https://orcid. \\ org/0000-0003-0041-728X
}

\begin{abstract}
RESUMEN
En la actualidad, hay escasez de investigaciones y estudios teóricos sobre cine infantil o familiar, lo cual dificulta la concreción de desarrollos curriculares sobre la materia que permitan la actualización de la formación docente y la utilización de estas producciones en el aula. Por tanto, el objetivo principal de este trabajo fue indagar sobre la incidencia que tuvo la utilización de técnicas de animación en la creación de películas infantiles o familiares que reescribieron obras de la literatura infantil y juvenil fantástica, desde finales del siglo pasado, y se difundieron en España. Al respecto, se plantea un diseño metodológico mixto, basado en una investigación ex post facto con orientación descriptiva, y el análisis de contenido de productos de carácter verbo-icónico (películas) e impresos (obras literarias). Los resultados indican que hay una tendencia creciente por la reescritura en imagen real, y el empleo de técnicas de animación que introducen efectos visuales para salvar las dificultades inherentes al proceso de recrear en la gran pantalla eventos, personajes o escenarios imposibles y hacerlos pasar por reales. En todo caso, el fenómeno adaptador es una realidad constante y asidua que condiciona y determina el proceso de socialización del individuo. Por tanto, es fundamental estudiar dicho fenomeno para la superación de las carencias educativas en este sentido y el desarrollo de programaciones didácticas eficaces.
\end{abstract}

Palabras clave: cine; estética de la imagen; literatura infantil; literatura fantástica; literatura juvenil; reescritura fílmica; técnicas de animación.

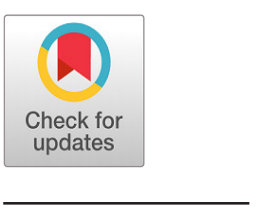

Recibido: 2021-03-13 / Aceptado: 2021-05-27 / Publicado: 2022-02-11

https://doi.org/10.17533/udea.ikala.v27n1a09

Editora: Doris Correa, Universidad de Antioquia, Medellín, Colombia

Derechos patrimoniales, Universidad de Antioquia, 2022. Este es un artículo en acceso abierto, distribuido según los términos de la licencia Creative Commons BY-NC-SA 4.0 Internacional. 


\begin{abstract}
Currently, there is a lack of research and theoretical studies on children and family movies, which makes it difficult to point out curricular developments on the subject which allow the updating of teacher training programs and the use of those productions in the classroom. Given this gap, this work aims to inquire about the incidence of animation techniques on the development of children and family movies which rewrote children's and youth literature for the big screen since the end of the last century, in Spain. In this regard, a mixed methodological design is proposed, based on ex post facto research with a descriptive orientation and content analysis of verbo-iconic (films) and printed (literary works) products. The results indicate that there is a growing trend for rewriting in real image and for the use of animation techniques that introduce visual effects with the purpose of overcoming the difficulties inherent in the process of recreating, on the big screen, events, characters or impossible scenarios and making them pass for real. In any case, the adaptation phenomenon is a constant and assiduous reality that conditions and determines the process of socialization of the individual. Therefore, it is fundamental to study this phenomenon to overcome educational deficiencies in this sense and to develop effective didactic programming.
\end{abstract}

Keywords: cinema; aesthetics of image; children's literature; fantastic literature; youth literature; filmic rewriting; animation techniques.

\section{RÉSUMÉ}

Compte tenu du manque de recherches et d'études théoriques sur le cinéma d'enfants ou de famille, qui rend difficile de préciser les développements curriculaires sur le sujet qui permettent la mise à jour de la formation des enseignants et l'utilisation de ces productions en classe, l'objectif principal de ce travail est de s'enquérir de l'incidence que l'utilisation des techniques d'animation a pour la création de films pour enfants ou familiaux qui réécrivent des œuvres de la littérature fantastique pour enfants et jeunes, depuis la fin du siècle dernier, avec diffusion dans l'État espagnol, en tenant compte de l'esthétique de l'image résultante et son adéquation aux différents groupes d'âge. À cet égard, une conception méthodologique mixte est proposée, basée sur une recherche ex post facto à orientation descriptive, basée sur l'analyse de contenu de produits verbo-iconiques (films) et imprimés (œuvres littéraires). Les résultats indiquent qu'il existe une tendance croissante à la réécriture en image réelle, qui utilise des techniques d'animation afin d'introduire des effets visuels pour surmonter les difficultés inhérentes au processus de recréer, sur grand écran, des événements, des personnages ou des scénarios impossibles et les rendre passer pour de vrai Dans tous les cas, le phénomène de l'adaptateur est une réalité constante et assidue qui conditionne et détermine le processus de socialisation de l'individu, dont l'étude et l'attention sont fondamentales pour surmonter les carences éducatives en ce sens et le développement d'une programmation didactique efficace.

Mots clés : cinéma ; esthétique des images; littérature d'enfance; littérature fantastique; littérature de jeunesse; réécriture filmique; techniques d'animation.

\section{RESUMO}

Diante da carência de pesquisas e estudos teóricos sobre cinema infantil ou familiar, o que dificulta a especificação de desenvolvimentos curriculares sobre o tema que permitam a atualização da formação de professores e o uso dessas produções em sala de aula, o objetivo principal deste trabalho é indagar sobre a incidência que 
o uso de técnicas de animação tem para a criação de filmes infantis ou familiares que reescrevem obras de literatura infanto-juvenil fantástica, desde finais do século passado, com difusão no Estado espanhol, tendo em conta a estética do a imagem resultante e sua adequação para diferentes faixas etárias. Nesse sentido, propõe-se um desenho metodológico misto, baseado em pesquisa ex post facto com orientação descritiva, a partir da análise de conteúdo de produtos verboicônicos (filmes) e impressos (obras literárias). Os resultados indicam que há uma tendência crescente de reescrita em imagem real, que utiliza técnicas de animação para introduzir efeitos visuais para superar as dificuldades inerentes ao processo de recriar, na tela grande, eventos, personagens ou cenários impossíveis e tornálos passe pra valer De qualquer forma, o fenômeno adaptador é uma realidade constante e assídua que condiciona e determina o processo de socialização do indivíduo, cujo estudo e atenção são fundamentais para a superação de deficiências educacionais nesse sentido e o desenvolvimento de uma programação didática eficaz.

Palavras-chave: cinema; estética da imagem; literatura infantil; literatura fantástica; literatura juvenil; reescrita fílmica; técnicas de animação. 


\section{Introducción}

En el año 2019, la Academia de las Artes y las Ciencias Cinematográficas de España publicó Cineyeducación, un documento marco para el proyecto pedagógico sobre dicho tema, con el objetivo de instar al Gobierno central y a las comunidades autónomas a que implantaran planes educativos referidos a la enseñanza audiovisual y a que los desarrollaran en cada ámbito autonómico, con el propósito de poner fin a las profundas carencias del sistema educativo en este asunto. Este documento destaca que es importante diferenciar el rol específico del lenguaje fílmico respecto al uso común del medio audiovisual, e incluye la alfabetización cinematográfica como uno de los tres tipos que engloba la alfabetización audiovisual, además de la visual y la televisiva (Lara et al., 2019).

Además, en sintonía con la división que recoge Ana M. Camuñas García-Miguel (2017) en cuanto a la doble posibilidad de utilización pedagógica del cine como contenido en sí mismo o recurso educativo transversal, el documento concluye que los cursos ofrecidos por los centros de formación continua de las consejerías educativas tienden a trabajar el cine de forma transversal, principalmente como recurso ligado a los valores y a la salud, y no de modo curricular, como contenido. Esta doble consideración se puede apreciar en propuestas didácticas actuales, como las desarrolladas por García Arias (2020) o Núñez-Gómez et al. (2020), que asumen el cine como recurso educativo para la educación en valores, al identificarlo como fenómeno social. En este sentido, entre las mayores dificultades para la alfabetización audiovisual, se encuentran la preparación de los docentes y la escasez de materiales didácticos o de orientaciones metodológicas (Guichot y Álvarez, 2002; Pérez Millán, 2014).

En el caso concreto del cine como contenido educativo, la Comisión Europea (2013) define la alfabetización fílmica como el nivel de comprensión de una película, la capacidad de tener estrategias para elegir películas, la competencia para ver y analizar críticamente su contenido, el lenguaje cinematográfico y los aspectos técnicos, así como la capacidad de utilizar estos recursos en la producción creativa de imágenes en movimiento.

Teniendo en cuenta esta noción y los contenidos propios de la competencia en comunicación audiovisual acerca del lenguaje propio del cine (Ferrés Prats, 2007; Marfil Carmona, 2008; Oliva Rota, 2006), el desarrollo de la competencia fílmica lleva implícitos la adquisición de distintos saberes, entre los que se encuentran los conocimientos culturales, historicistas y enciclopédicos; la identificación, el conocimiento y la interpretación del uso fílmico del lenguaje audiovisual; y el conocimiento de las relaciones hipertextuales entre películas y otras manifestaciones artísticas, como la literatura o la novela gráfica. Todos ellos se contemplan en el desarrollo de esta investigación, que pueda también funcionar como un recurso para mediadores (docentes y familias) entre cine e infancia, especialmente recomendable para obtener los valores del cine recogidos por Lucía María Vicent Martín (2016). Entre ellos, destacamos la necesidad de informarse antes de elegir la película que se va a utilizar con el alumnado para asegurar su adecuación a los intereses y las capacidades del espectador, y su viabilidad en el marco de unos objetivos curriculares concretos.

En efecto, el conocimiento integral de las obras literarias y fílmicas creadas parala infancia y la juventud, o consideradas así tras un proceso de apropiación, es fundamental para la realización de programaciones curriculares exitosas. En los últimos años, el interés académico e investigador por la literatura infantil y juvenil (LIJ), con el objetivo de evitar la instrumentalización de estas producciones en las aulas, ha crecido exponencialmente, mientras el tratamiento y estudio del cine infantil y familiar sigue respondiendo a iniciativas aisladas.

Ante la escasez de estudios similares y con el propósito de motivar el interés de análisis de las producciones fílmicas dirigidas a la infancia y sus 
familias como obras de arte con interés educativo, el objetivo del presente estudio es indagar sobre la incidencia y posibles funciones de la utilización de técnicas de animación en la creación de películas infantiles o familiares que reescriben obras literarias infantiles o juveniles, con eventos, personajes o escenarios propios de la literatura fantástica, a partir de un corpus compuesto por un total de 75 producciones estrenadas en España entre los años 1996 y 2019.

\section{Marco teórico}

Para profundizar en los ámbitos básicos para la comprensión del estudio, en este apartado nos ocupamos de las relaciones entre la literatura fantástica con el público infantil y juvenil, y con la reescritura fílmica.

\section{La literatura fantástica y el público infantil y juvenil}

178 Los grandes teóricos de lo fantástico literario coincidían en que este se construye sobre la noción de lo imposible (Furtado, 1980; Hume, 1984; Irwin, 1976; Jackson, 1986; Manlove, 1975, 1983; Todorov, 1970/1994). Según Todorov, "lo fantástico es la vacilación experimentada por un ser que no conoce más que las leyes naturales, frente a un acontecimiento aparentemente sobrenatural" (1970/1994, p. 24). Por tanto, ese tiempo de duda corresponde al único momento de existencia de lo fantástico, que se decide por uno de los subgéneros colindantes gracias a la decisión del personaje o el lector: si las leyes de la realidad quedan intactas y, de alguna manera, permiten explicar los fenómenos representados, se estaría en el campo de influencia de lo extraño; si es necesario admitir nuevas leyes para explicar el fenómeno, la obra pertenecería al género maravilloso. Si se aplica esta taxonomía a la diversidad de obras literarias fantásticas infantiles o juveniles, la mayoría de ellas se aglutinan en el ámbito de lo maravilloso.

Motivados por las limitaciones de los estudios de lo fantástico existentes y tras el inesperado éxito de sagas como Harry Potter, de J. K. Rowling, o His Dark Materials de Philip Pullman, que hizo patente la existencia de una dimensión propia y autónoma de lo fantástico respecto a la literatura institucionalizada o de adultos, empezaron a sucederse estudios sobre literatura fantástica infantil y juvenil, que hacen especial referencia a los ámbitos inglés y estadounidense desde una perspectiva cronológica (Egoff, 1988; Johansen, 2005; Levy y Mendlesohn, 2016; Manlove, 2003; Sachiko Cecire, 2019).

Al mismo tiempo, otro grupo de investigadores se centraba en aproximarse al concepto desde una perspectiva teórica, para así poder desarrollar una propuesta taxonómica de estas narrativas que, en términos generales, respondían a la existencia (evidente o sugerida) de un mundo secundario-fantástico (Gamble y Yates, 2008; Held, 1985; Nikolajeva, 1988). Así, el concepto del mundo secundario-fantástico fue acuñado por primera vez por J. R. R. Tolkien en el ensayo "On Fairy Stories" (1983), quien describe este mundo secundario como lo real descontextualizado a través del poder de la imaginación, de modo que "man becomes a sub-creator" (p. 122). Además, también hace referencia al concepto de "willing suspension of disbelief” (p. 132), acuñado en 1817 por el poeta y filósofo Samuel Taylor Coleridge, que se utiliza para describir el proceso por el cual una persona suspende temporalmente su sentido de lo real, con el objetivo de ser capaz de apreciar una historia imposible o, más concretamente, una ficción fantástica.

La complejidad a la hora de tipificar las relaciones que se establecen entre los mundos real-primario y secundario-fantástico hizo que autores como Pamela S. Gates et al. en Fantasy Literature for Children and Young Adults (2003) o Maria Nikolajeva, en el artículo "The Development of Children's Fantasy” (2012), optaran por ofrecer clasificaciones con base en aspectos más concretos.

En el primer caso, Gates et al. (2003) diferenciaron entre cuentos de hadas, que, a su vez, se 
dividían en cuentos de hadas populares provenientes de la tradición oral y cuentos de hadas escritos por autores concretos; fantasias mixtas, cuando se combina fantasía y realidad de distintas maneras y en distintas proporciones, con las subcategorías de viajes, transformaciones, animales parlantes y magia; y las narrativas que siguen tradiciones heroico-éticas, que responden a adaptaciones de la tradición heroica o mitológica, en las que se recurre a un mundo con figuras de orden superior y héroes de edades próximas al lectorado más joven, que representan el bien en lucha contra el mal.

Por su parte, Nikolajeva (2012) decide explicar el fenómeno mediante el agrupamiento de obras según sean de viajes en el tiempo, fantasías de animales, juguetes o personas diminutas, mundos alternativos y fantasías visuales, extendiendo la consideración de los álbumes ilustrados como una categoría en sí misma y situándolos en un lugar relevante dentro de la tipología propuesta.

En efecto, Lucas Gagliardi (2020) señala, como uno de los principales problemas de las definiciones restrictivas de lo fantástico, su incapacidad para poder explicar su configuración en textos recientes; y habla de un segundo grupo de teorías “integradoras". De entre ellas, destaca la propuesta de la investigadora Farah Mendlesohn, desarrollada en el volumen Rhetorics of Fantasy (2008), donde ejemplifica la taxonomía con obras fantásticas, sean infantiles o no. En este sentido, cabe destacar que la diferencia entre la construcción de narrativas fantásticas para público infantil, juvenil o adulto no reside en las técnicas de inclusión de lo fantástico o la forma y la presencia del elemento imposible, que se pueden entender como construcciones análogas (Gates et al., 2003, p. 9). Mendlesohn toma como principal referencia la obra de Brian Attebery (1980, 1992, 2014), quien propone la definición de las categorías como fuzzy sets, es decir, "categories defined not by a clear boundary or any defining characteristic but by resemblance to a single core example or group of examples (strategies)" (2014, cap. 1). También sostiene que la premisa fundamental de la que parte la fantasía es la de contar cosas que no solo no han sucedido, sino que además no podrían haber sucedido de ninguna manera.

En su libro, la investigadora relaciona cinco modos o categorías de lo fantástico: portal-quest fantasy, que engloba las nociones de portal fantasy, un mundo fantástico al que se accede por medio de un portal, y quest fantasy, cuando el protagonista parte de una vida ordinaria y entra en contacto directo con lo fantástico a partir de un viaje exploratorio; inmersive fantasy, cuando lo fantástico no recibe ningún tipo de explicación, ya que está normalizado dentro de la realidad de la ficción; intrusion fantasy, cuando lo fantástico irrumpe en la dinámica del mundo de la ficción, entendido como ordinario y predecible, que vuelve a la normalidad cuando el elemento o personaje fantástico regresa a su lugar de origen; liminal fantasy, cuando, en un mundo que se identifica como real, lo fantástico da señales de existencia, pero no se confirma como tal, causando en el lector una continua sensación de extrañeza; y el grupo de los irregulars, obras que no cuentan con suficientes puntos en común como para crear una nueva categoría.

La cercanía y la predisposición de los más jóvenes por las modalidades genéricas de lo fantástico contrastan con el desprecio manifiesto de la crítica literaria hacia la literatura fantástica calificada como un subgénero. David Pujante, en su artículo "Las inquisiciones de la literatura fantástica” (2016), reflexiona sobre el maltrato secular que ha sufrido la literatura fantástica en la literatura occidental, incidiendo en las críticas a sus lectores, por consumirla, y a los editores y a escritores, por satisfacer la demanda. No obstante, a partir del éxito de sagas juveniles como Juego de tronos, Crepúsculo o Los juegos del hambre, concluye que "los jóvenes que viven en este mundo nuevo, nada reconocen de suyo en todas las inquisiciones de la literatura fantástica a las que nos hemos referido previamente" (Pujante, 2016, p. 60). 
En el caso de la infancia, la fantasía es una constante necesaria y positiva, que va mutando su presencia y materialización en la ficción, para adaptarse a los cambios evolutivos que se van sucediendo en el proceso de crecimiento. Jacqueline Held ha defendido con rotundidad la importancia de la fantasía literaria en la estimulación del pensamiento crítico, de la inteligencia y de las capacidades creativas de los más jóvenes, y afirma que "las raíces de la fabulación no se vuelven racionales intentando suprimirlas de la infancia, sino, por el contrario, ayudando al niño a manejar esa fabulación con más y más finura, alejamiento y distancia” (1985, p. 36). En esta línea, la Tabla 1 recoge las cuatro fases que reconoce la psicología evolutiva — primera infancia, segunda infancia, tercera infancia y adolescencia-, en relación con las etapas específicas del desarrollo cognitivo delimitadas por Jean Piaget (1933/2001, 1964/1991), las preferencias temáticas, estructuras literarias y diseños de libros correspondientes según la clasificación de Cerrillo y Yubero (2007), las etapas lectoras (Hernández López, 2015) y los ciclos literarios en la infancia (Medina, 1957).

\section{La reescritura fílmica de la literatura fantástica}

Wells (2007) afirmaba que el lenguaje de la animación se caracteriza por ser el arte de lo imposible: es capaz de mostrar una representación distinta de la realidad y de crear mundos que transgreden los códigos y las convenciones naturales, donde todo lo imaginable es factible. En este sentido, la propia imposibilidad de lo fantástico implica que la "reescritura fílmica" de lo fantástico literario mediante la imagen en vivo, es decir, la grabación directa de escenarios y personajes, sea insuficiente, y se haga necesario recurrir a distintas técnicas de animación. En efecto, la recurrencia de la utilización de la animación en la producción de estas obras se hace evidente en la gran presencia de reescrituras fílmicas de la LIJ fantástica en la relación de nominados y premiados de los principales galardones internacionales a largometrajes animados (Oscar,
Golden Globes, Annie y BAfTA), estudiados por G-Pedreira (2020), quien explica que una de las ventajas frecuentes, tras el estreno de la reescritura fílmica de una obra literaria, es la reedición del hipotexto de partida y, para algunas obras, la revivificación de obras parcialmente olvidadas o la difusión internacional de otras.

$\mathrm{Al}$ igual que en el estudio mencionado y siguiendo la reflexión realizada por Pérez Bowie (2010), en este trabajo se prioriza el término "reescritura fílmica", en detrimento del de "adaptación cinematográfica”, ya que aquel hace referencia a un proceso de apropiación y de revisión consistente en transformar y trasponer, en mirar desde un nuevo contexto un texto precedente, por medio de una serie de operaciones sobre los hipotextos literarios, que "impliquen una intervención a fondo basada en una poética personal y, dotada, por consiguiente, de un cierto grado de reflexividad" (Pérez Bowie, 2010, p. 39).

En este sentido, Álvaro Cadavid defiende la necesaria reconciliación del cine y la literatura, y la inoperancia de la fidelidad como criterio de valoración crítica de hipertextos fílmicos, al considerar la reescritura fílmica como "un instrumento para difundir y ampliar los mercados de los textos literarios entre los espectadores del cine" (2000, p. 112).

Como ya hemos adelantado, el diálogo intertextual (Stam, 2000) entre la literatura infantil y juvenil y el cine ha sido una constante desde los comienzos del siglo Xx, ya que, en palabras de McCallum, "historically, film media has always had a partiality for adaptation of literary sources, especially of canonical or 'classic' literary texts and of children's texts, with some of the earliest film adaptations being of children's novels" (2018, p. 1).

Por tanto, reconocemos la animación como una de las principales opciones técnicas a la hora de llevar a la gran pantalla historias, lugares o eventos fantásticos; además de que un alto porcentaje de estas producciones son catalogadas como cine infantil o familiar. 
Tabla 1 Correspondencia entre las cuatro fases reconocidas por la psicología evolutiva, las etapas específicas del desarrollo cognitivo, las preferencias temáticas, estructuras literarias y diseños de libros, las etapas lectoras y los ciclos literarios en la infancia

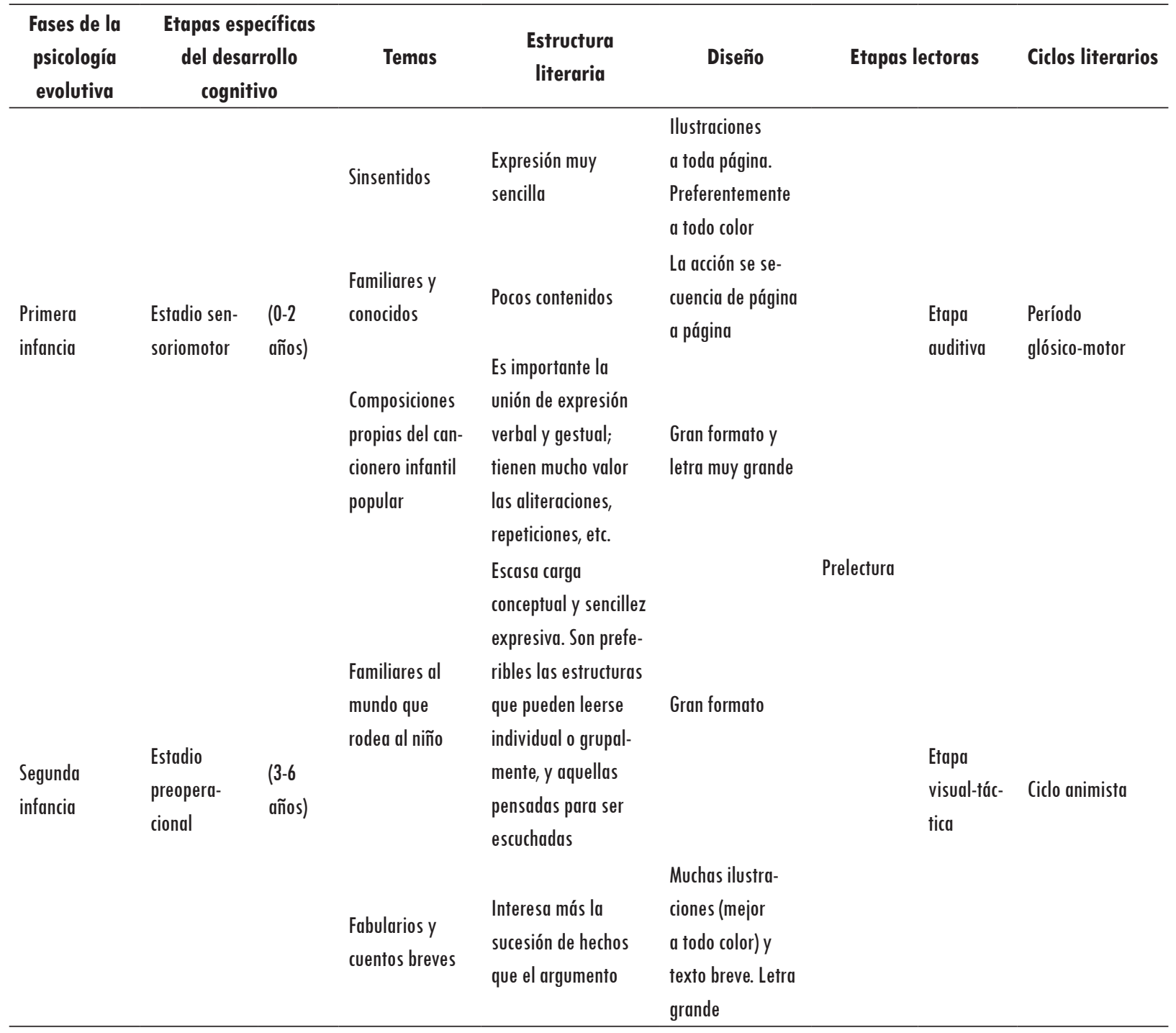


Tabla 1 Correspondencia entre las cuatro fases reconocidas por la psicología evolutiva, las etapas específicas del desarrollo cognitivo, las preferencias temáticas, estructuras literarias y diseños de libros, las etapas lectoras y los ciclos literarios en la infancia (Cont.)

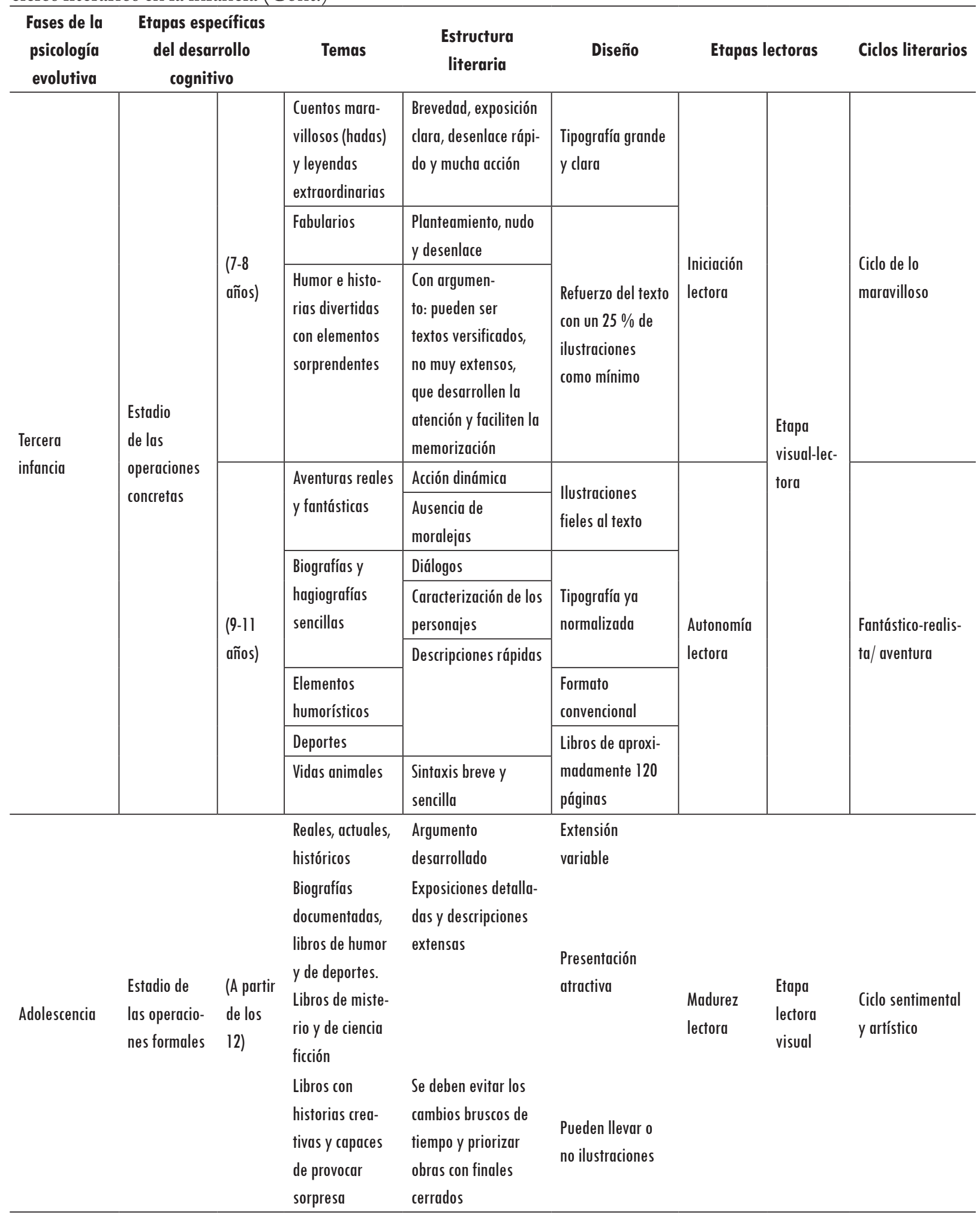

Fuente: Cerrillo y Yubero (2007), Hernández López (2015), Medina (1957) y Piaget (1933/2001, 1964/1991). 
A partir de la revisión de distintos estudios teóricos que han explorado este fenómeno (Arendt et al., 2010; Bazalgette y Staples, 1995; Brown, 2012, 2017, 2019; Brown y Babington, 2015; Donald y Seale, 2013; Hermansson y Zepernick, 2019; Krämer, 2002; Newton, 2006; Parry, 2013; Rodríguez Rosell y Melgarejo Moreno, 2010) y las recomendaciones por franjas de edad que califican la idoneidad de las producciones cinematográficas, entendemos el cine infantil como el conjunto de producciones que puede ser visionado por la infancia (hasta los 12 años), mediante su adecuación en cuanto a contenido y forma, bien dirigiéndose a los más pequeños de modo explícito (películas con el distintivo "especialmente recomendadas para la infancia") o implícito (películas familiares). A su vez, el cine familiar agrupa las producciones ambivalentes que se sitúan, al mismo tiempo, dentro del campo de influencia de las películas para adultos y de las películas infantiles (calificaciones " $\mathrm{A}$ ": apta para todos los públicos y "7": no recomendada para menores de 7 años)”, denominaciones que pueden variar en función del país.

El interés educativo de estas producciones en las etapas de educación obligatoria ha ido en aumento durante los últimos años, a la vista del protagonismo que tienen en los momentos de ocio de los más jóvenes y las consecuencias del menosprecio ingenuo y generalizado del poder socializador del entretenimiento (Yubero, 2005). En esta línea se pronuncian autores como Ambròs y Breu (2007), González-Fernández et al. (2018), López Serrano (2019) y Ortega Carrillo y Pérez García (2013), quienes sostienen que el analfabetismo mediático ${ }^{1}$ es el propio de nuestros tiempos, y que la capacidad del cine de influir en sus espectadores, unida a la creciente influencia sociológica sobre las actitudes y los hábitos de la ciudadanía, hacen de la evolución y la mejora de la presencia e inclusión

1 Ambròs-Pallarès (2020, p. 10) explica que el alfabetismo mediático está centrado en la escuela, mientras el transmedia tiene el foco de desarrollo en los momentos fuera de las aulas, ya que se asienta sobre los estudios culturales y la ecología de los medios. del cine en las aulas una necesidad acuciante. Además, también resaltan que existen una disonancia evidente entre el interés y las posibilidades educativas y el uso real como contenido educativo, por lo que se hace necesario un aumento y mejora de la sensibilización y responsabilidad del profesorado, a la hora de planificar acciones educativas completas, con utilidad teórico-práctica.

Por otra parte, para cumplir con el propósito principal de este estudio, se ha tenido en consideración la mejora de las posibilidades técnicas de la animación y la consecuente tendencia actual en la creación de reescrituras fílmicas de la literatura fantástica, que ha pasado de producir obras donde los códigos de la animación dominan la estética de la película, a otras donde son usados para salvar los problemas derivados de mostrar elementos imposibles, pero que buscan una representación realista de lo fantástico. Por tanto, se puede hablar de distintas categorías, en función de la intención que subyace en la utilización de unas determinadas técnicas de animación y la estética del resultado final:

- Películas de estética animada (función subversiva): el resultado final es una película realizada, de manera íntegra, mediante técnicas de animación que determinan la construcción estética de la obra. En ningún momento hay duda de que no estamos ante imágenes reales.

- Películas de estéticarealista (funciónnormalizadora): el resultado final es una película donde la utilización de técnicas de animación es imperceptible en la construcción estética de la obra, formando parte de los efectos especiales, en concreto, visuales digitales. Según Manuel Armenteros Gallardo (2011, p. 1), los efectos especiales son aquellos artificios que dan apariencia de realidad a ciertas escenas, pudiendo dividirse en visuales y sonoros. Los efectos visuales son procesos por los cuales se integran las tomas de acción en vivo y las imágenes generadas por ordenador, con el objetivo de crear ambientes que parezcan realistas, mientras los efectos sonoros se encargan de la reconstitución artificial de efectos 
acústicos que acompañan la imagen en movimiento. El autor también señala que, para que las representaciones resulten convincentes y eficaces, es necesario el naturalismo de la representación virtual, la indistinción en el plano de la representación y la integración imperceptible en el espacio de la historia. Los realizadores recurren a la animación digital para suplir la naturaleza de los elementos fantásticos y conseguir la máxima referencialidad posible, obteniendo películas donde lo imposible es representado de manera "realista" (p. 1).

- Películas de estética mixta (función adaptativa): el resultado final es una película donde la imagen real y la imagen animada se integran para la construcción estética final, de modo que ambas comparten protagonismo. No es posible la concepción de la obra sin una de ellas, y la recurrencia de una u otra depende de las decisiones tomadas por la persona a cargo de la dirección sobre cómo interpreta, a nivel audiovisual, la retórica de lo fantástico.

En un contexto como el actual, en el que las posibilidades de la animación digital han revolucionado la manera de hacer cine, no solo de animación, las funciones atribuidas a cada categoría estética responden al interés del equipo de producción de suscitar una manera de ver el filme. En el caso de películas donde la estética animada domina durante todo el metraje, se establece un cierto distanciamiento con respecto a la realidad del espectador desde el comienzo de la película. En un mundo animado, todo es posible y la sucesión de eventos fantásticos (intrusivos o no) no supone un impacto a nivel perceptivo-visual.

No obstante, partiendo del carácter subversivo atribuido a la literatura fantástica, en tanto que se organiza "en torno a un encuentro conflictivo entre dos órdenes ontológicos de naturaleza diferente y que en el texto no puede recibir una explicación unívoca" (Martínez, 2010), la animación posee la capacidad transgresora de mostrar una realidad irrealizable y darle veracidad y coherencia mediante una representación estética particular. En efecto, la subversión propia de la literatura fantástica se intensifica al ser representada audiovisualmente mediante la animación. En este sentido, en el artículo "Entre lo siniestro y lo subversivo. Categorías estéticas del cine de animación híbrido", de Viñolo Locubiche y Duran-Castells (2013), se señala que la potencialidad subversiva de la imagen animada se explica mediante la hipótesis del "valle tenebroso", utilizada en el campo de la robótica y la animación para explicar la repulsión que se experimenta ante seres demasiado semejantes al ser humano, pero con algo ineludiblemente artificial. Por debajo de este nivel de parecido, la mente humana sentiría empatía por los seres representados, como ocurre con las marionetas o los dibujos animados.

Los mismos autores también ofrecen una esclarecedora clasificación de las posibles relaciones entre la imagen animada y la imagen referencial, que incluyen la disgregación, la colaboración ambiental, la colaboración irrealista y la colaboración fotorrealista (Viñolo Locubiche y Duran-Castells, 2013, pp. 45-47). En la disgregación, los significados de los dos niveles de la imagen no se mezclan, de modo que se mantienen los códigos visuales de manera independiente, mientras en la colaboración ambiental tampoco hay interacción, pero sí reacción de uno de ellos, ya que es utilizada para la ambientación visual de efectos atmosféricos, multitudes, etc. La falta de interacción entre las imágenes resta la importancia de estas dos categorías para nuestro trabajo, por lo que nos centramos en las restantes: la colaboración fotorrealista, cuando se simula de forma efectiva la existencia de ambas imágenes en la misma unidad de espacio y tiempo, compartiendo códigos de representación e interactuando físicamente; y la colaboración irrealista, cuando la imagen animada y la referencial simulan coexistir en la misma unidad de espacio y tiempo, pero se mantienen visualmente separadas. En este caso, se obtiene una imagen profundamente irrealista, aun cuando hay interacción entre los distintos elementos, para aumentar la sensación de estar físicamente en el mismo plano. 
La colaboración fotorrealista es propia de las películas de estética realista, ya que las técnicas de animación tienen la función de normalizar lo fantástico y hacerlo pasar por real. La única manera de saber que lo que estamos viendo no es la imagen referencial, es la propia imposibilidad de la existencia o sucesión de los personajes o eventos representados, ya que transgreden las normas naturales que rigen el mundo real.

Por último, aunque las películas de estética mixta responden a una colaboración profundamente irrealista que nos deja claro lo que es animación y lo que no, en ocasiones se utiliza para reforzar el carácter intrusivo y transgresor de lo fantástico. Es decir, se emplea la imagen animada para la recreación visual de lo fantástico y la imagen referencial para la representación del mundo primario-realista.

\section{Método}

Con el objetivo de asentar el trabajo en un modelo conceptual que garantice la rigurosidad del estudio, se plantea un diseño metodológico mixto, basado en una investigación ex post facto - después del hecho- que utiliza, principalmente, el análisis de contenido (Bardin, 1991; Cáceres, 2003; Krippendorff, 1990; López Noguero, 2002; Mayring, 2000; Pérez Serrano, 1994; PiñeiroNaval, 2020; Richard, 2009). Se trata de una técnica que utiliza instrumentos y procedimientos sistemáticos y objetivos de descripción para el tratamiento explícito e implícito del contenido de los mensajes, con el objetivo de interpretar sus elementos constituyentes en relación con las condiciones de producción o recepción mediante la inferencia.

Aunque ambos se centran en la comunicación, el análisis de contenido se diferencia del análisis del discurso en que no se restringe al plano verbal, oral o escrito, pudiendo aplicarse a otros materiales como la pintura, el cine o la música. Así, Pablo Francescutti (2019) lo reconoce como uno de los métodos de análisis textual más recurrentes en el estudio de narraciones audiovisuales, especialmente en el trabajo con corpus numerosos.

En el presente estudio, el análisis de contenido se lleva a cabo sobre documentos de carácter verboicónico, películas en concreto, pero también a documentos impresos, ya que se trata de reescrituras fílmicas de hipotextos literarios.

Respecto a la recogida de información, se seleccionó una muestra representativa de películas infantiles o familiares, elaboradas únicamente mediante técnicas de animación o por medio de la colaboración irrealista o fotorrealista de la imagen animada y la imagen referencial, aplicadas durante la fase de producción o posproducción, que reescriben obras de la literatura fantástica infantil o juvenil, y se han distribuido por los cines del territorio español.

El acote temporal, que incluye las producciones estrenadas en España hasta finales de 2019, comienza en marzo de 1996, fecha en la que se estrena Toy Story en nuestro país, el primer largometraje de Pixar y un hito histórico en la historia del cine de animación. Fue la primera película realizada íntegramente con animación digital y un salto adelante radical, tanto en el aspecto técnico como artístico. A partir de ahí, las demás productoras empezaron a cuestionarse la manera en que venían haciendo su trabajo (Paik, 2007), con el objetivo de poder competir con Pixar y prepararse para los cambios inevitables que iban a traer las posibilidades de la innovación digital.

Por otra parte, dentro del grupo de reescrituras que cumplen estas características, se ha filtrado la muestra a partir de criterios de selección excluyentes: quedan fuera las reescrituras de historias de la tradición oral (solo obras de autor), los formatos de corta o media duración (solo largometrajes) y las obras para adultos que fueron primero adaptadas al nuevo público y después reescritas para el formato audiovisual (solo hipotextos literarios de la LIJ). No obstante, se mantienen obras que pueden entrar dentro del alcance de la literatura 
juvenil a partir de la consideración de obras "ganadas", es decir, aquellas que originalmente no fueron pensadas para los más jóvenes, o mediante su identificación con el fenómeno crossover (Beckett, 2009; Falconer, 2009, 2010; Ramos y Navas, 2015), cuyas propuestas literarias ofrecen distintos niveles de lectura que las hacen adecuadas para lectorado de cualquier edad. Además, se omiten los textos literarios de partida que pertenecen a modalidades narrativas, en concreto novelas, cuentos o álbumes ilustrados, y las secuelas, ya que tienden a mantener la estética de sus predecesoras y contribuirían negativamente a la caracterización del fenómeno estudiado.

\section{Recolección y análisis de los datos}

Los datos analizados con respecto a cada película de la muestra han sido: mes y año de estreno en España, título, año, recomendación de edad, dirección, categoría estética de la imagen, y el título, el año de publicación y la autoría del hipotexto literario de partida (véase Anexo).

Para la obtención de los datos, además de la lectura y el visionado directo de las obras relacionadas, se han utilizado dos bases de datos cinematográficos: una a nivel internacional, Internet Movie Database (s. f.), y otra a nivel nacional, realizada por el Instituto de la Cinematografía y de las Artes Audiovisuales (s. f.).

Las 75 películas de la muestra han sido producidas, en su mayor parte, entre 2010-2019 (41 del total: 54, \%); 29 entre 2000 y 2009 (38, \%); y las 5 restantes, entre 1996 y 1999 (6, \%). En cuanto a los hipotextos de partida, 16 fueron escritos a partir del año 2000 (21,); 35 entre 1950 y 2000 (46,); 15 entre 1900 y 1950 (20\%), y 9 antes de 1900 (12\%).

En relación con los países de producción, aunque destaca notoriamente Estados Unidos por cantidad, en la mayoría de ocasiones lo hace en colaboración con otros, como Reino Unido, Canadá, Australia, Nueva
Zelanda. Además, también se repiten en varias ocasiones España, Francia, Japón o Alemania.

\section{Resultados y discusión}

Del total de películas que recoge la muestra, 38 son de estética animada (50,\%), 35 de estética realista (46, \%) y 2 de estética mixta (2, \%). No obstante, si nos centramos en las películas a partir de 2010, 24 pertenecen al primer grupo, 18 al segundo y ninguna al tercero. Durante los años más recientes, el crecimiento exponencial de las reescrituras en imagen real se hace aún más evidente, ya que se vuelven mayoritarias en los últimos dos años.

Por otra parte, según las bases de datos utilizadas, del total de producciones, 56 están calificadas como "Apta para todos los públicos" (74, \%) y las 19 restantes están recomendadas para mayores de 7 años (9,\%). Dentro del primer grupo, 25 de las películas calificadas como "A" han recibido el distintivo "i”, que significa "especialmente recomendada para la infancia” (44,6 \%). De ellas, 17 son películas de estética animada y, casi la mitad, 8 en total, de estética realista. Si nos fijamos en las películas cuya calificación indica “+7”, solo ha conseguido el distintivo, How To Train Your Dragon (2010), una producción creada mediante imagen generada por ordenador 3D. De las 18 restantes, 6 son de estética animada, y 12, justo el doble, de estética realista.

Los resultados obtenidos pusieron de relieve varios aspectos de interés para entender el fenómeno adaptador analizado. Por una parte, ante la evidencia de que la reescritura fílmica de eventos, personajes y escenarios propios de la literatura fantástica siempre necesita de la aplicación de técnicas de animación, se ha podido observar cómo la tendencia ha pasado de la utilización única de técnicas de animación tradicional, especialmente los dibujos animados, hacia la aplicación de técnicas fotorrealistas que, junto a la imagen referencial, dan como resultado producciones de estética realista. Esta evidencia responde al creciente avance en cuanto a las posibilidades técnicas de la animación 
y al abandono de los métodos más tradicionales a favor de otros digitales más sofisticados.

En efecto, muchas de las reescrituras de clásicos producidas desde el cambio de siglo han supuesto la renovación de otras propuestas anteriores realizadas mediante animación tradicional. De entre todas, destacan las desarrolladas por Walt Disney Pictures, que, además de cambiar a una nueva estética de la imagen, también ha decidido alejarse todavía más del hipotexto literario de partida, dando como resultado reescrituras libres, como sucede con Alice in Wonderland (2010) - con respecto a la película animada estrenada en 1951- o Dumbo (2019) — cuya versión animada vio la luz en 1941 - No obstante, también hay casos como The Jungle Book (2016), que se aproxima más a la historia según fue concebida por Ruyard Kipling (1894) que la propuesta animada de 1967.

En el caso de las dos películas de estética mixta que incluye la muestra, ambas han utilizado el distanciamiento de la estética animada y la imagen referencial para denotar el carácter intrusivo de los eventos o personajes fantásticos. Tanto en la película James and the Giant Peach como en Arthur et les Minimoys, cada niño protagonista adquiere su forma animada cuando modifica su tamaño y se transforma su apariencia, pero vuelve a ser interpretado por un niño actor cuando interactúa con su familia y demás humanos en el plano del mundo primario. Al final de las historias, lo fantástico se naturaliza en el mundo primario y podemos ver, en un mismo plano, las dos estéticas.

Por otra parte, las reescrituras fílmicas que recrean en la gran pantalla el mundo primario en conexión con distintos mundos secundarios-fantásticos con entidad en sí misma - como sucede con el mundo mágico de Harry Potter, el País de Nunca Jamás donde habita Peter Pan, el reino de Narnia a donde viajan los hermanos Pevensie, el País de las Maravillas a donde llega Alicia, el País de los Gigantes o el mundo mágico de $\mathrm{Oz}$ - presentan una imagen de estética realista que ayuda a la credibilidad de los eventos relatados. De este mismo modo, también han sido realizadas las representaciones de mundos propios de la alta fantasía o fantasía épica, como la Tierra Media o Alagaesia. No obstante, algunas de estas historias han sido elaboradas íntegramente mediante técnicas de animación, debido al tono cómico de las historias relatadas, como en Shrek; a la apuesta personal de un estudio concreto, como es el caso de Ghibli al recrear el reino de Ingary o el mundo de Terramar; o a la adecuación consciente a los gustos prioritarios de la infancia, que pueden intuirse en la manera de llevar a la gran pantalla las novelas protagonizadas por Hipo, escritas por Cressida Cowell.

A este respecto, la elección de un tipo de estética $\mathrm{u}$ otra parece relacionarse directamente con el público objetivo de las reescrituras fílmicas. Por esta razón, la muestra analizada sugiere una cierta correlación entre las películas familiares y especialmente recomendadas para la infancia y la estética animada, aunque en el caso de las reescrituras de hipotextos literarios fuertemente arraigados dentro del sistema literario infantil, que no suponen un distanciamiento excesivamente notorio de la historia anclada en el imaginario colectivo, mantienen su consideración de aptas para todas las edades y públicos, como en el caso de The Hundred and One Dalmatians, cuya versión animada producida también por Disney fue estrenada en 1996, o la película Where the Wild Things Are, a partir del famoso álbum escrito e ilustrado por Maurice Sendak. Otra diferencia sutil en esta línea es la que presentan los hipertextos fílmicos en animación e imagen real de obras como Der kleine Vampir o How the Grinch Stole Christmas, que aun siendo todas calificadas como "A", solo reciben el distintivo de especialmente recomendadas para la infancia las versiones animadas.

Por último, en cuanto a las calificaciones de edad, las novelas juveniles contemporáneas reescritas han sido realizadas, en su mayoría, mediante imagen referencial y técnicas fotorrealistas, guardando un reconocible nivel de dependencia con respecto al hipotexto literario y han sido calificadas para 
mayores de 7 años. Por ejemplo, la película protagonizada por Percy Jackson, la recreación fílmica de la novela de Ransom Riggs, la producción que reescribe la serie de libros de Cornelia Funke o las más recientes producciones basadas en $A$ Wrinkle in Time y The House with a Clock in its Walls. En todo caso, uno de los mayores inconvenientes en el momento de analizar este aspecto fundamental es la falta de consenso y las muchas discrepancias a la hora de establecer las calificaciones por edad, hasta el punto de que algunas producciones dejan de clasificarse como cine infantil o familiar, y pasan a ser recomendadas para mayores de 12 o 13 años en las más famosas plataformas de streaming donde se encuentran disponibles, como se puede observar en la Tabla 2.

Otro dato destacable, que hace referencia a la retórica del relato y a cómo se reescribe audiovisualmente, es la manera habitual de llevar a cabo la reescritura de álbumes ilustrados dirigidos a los más jóvenes, a partir de un proceso de ampliación de la trama y la estética animada. Suelen estar protagonizados por animales parlantes, pensantes o antropomórficos, a modo de fábulas, que se utilizan para reflejar y explorar los principios éticos y morales de los seres humanos (Shaw, 2010), y mantienen grandes dosis de ternura, inocencia y humor infantil, características muy presentes en los hipotextos literarios, como sucede en las reescrituras del álbum Horton Hears a Who!, de la serie Ernest et Célestine, del cuento de Ferdinand o de las historias de Peter Rabbit.

\section{Conclusiones}

Ante todo lo expuesto, podemos afirmar que los procesos de reescritura fílmica de la literatura infantil y juvenil son una realidad constante y transformadora del panorama de las producciones culturales de signo estético destinadas a público infantil. En efecto, las películas y otras narraciones audiovisuales protagonizan un gran porcentaje del tiempo de ocio de los más jóvenes, cuya recepción implica a otros agentes que actúan como mediadores, especialmente familias y docentes. En este sentido, la industria cinematográfica aprovecha esta realidad para centrar gran parte de su esfuerzo en ofrecer producciones para la infancia y sus familias, utilizando reiteradamente obras literarias anteriores exitosas y reconocidas, con el objetivo de limitar las variantes que pueden determinar la rentabilidad de su creación y difusión.

A lo largo del estudio, hemos visto cómo el interés por este tipo de producciones ha resultado en un grado alto de experimentación acerca de las técnicas de realización utilizadas. En el caso de la reescritura de la literatura fantástica, la retórica entre lo real y lo imposible propia de estas narraciones implica necesariamente la utilización de técnicas de animación que muestren en pantalla

Tabla 2 Diferentes calificaciones de edad de películas en bases de datos y plataformas de streaming

\begin{tabular}{|c|c|c|c|c|c|c|}
\hline Película & IMDB & ICCA & NETFLIX & HBO & PRIME & DISNEY+ \\
\hline Harry Potter and the Philosopher's Stone (2001) & A & A & $7+$ & 7 & 13 & - \\
\hline $\begin{array}{l}\text { The Chronicles of Narnia: The Lion, the Witch and the } \\
\text { Wardrobe (2005) }\end{array}$ & 7 & +7 & - & - & - & $12+$ \\
\hline Cuentos de Terramar (2006) & 7 & +7 & $13+$ & - & - & \\
\hline Percy Jackson \& the Olympians: The Lightning Thief(2010) & 7 & +7 & - & - & - & $12+$ \\
\hline The Hobbit: An Unexpected Journey (2012) & 7 & +7 & - & - & 13 & - \\
\hline Oz the Great and Powerful(2013) & 7 & +7 & - & - & - & $12+$ \\
\hline The Jungle Book (2016) & $\mathrm{Ai}$ & $\mathrm{Ai}$ & - & - & - & $12+$ \\
\hline Beauty and the Beast(2017) & $\mathrm{Ai}$ & Ai & - & - & - & $12+$ \\
\hline The Nutcracker and the Four Realms (2018) & $\mathrm{Ai}$ & Ai & - & - & - & $12+$ \\
\hline
\end{tabular}

Ai: película calificada como "A”, especialmente recomendada para la infancia. 
el aspecto de lo fantástico, producto de la imaginación creadora de su autor. El resultado son distintas estéticas en la imagen resultante cuya elección se ve condicionada, principalmente, por el público objetivo, las posibilidades técnicas existentes en el momento de realización de la obra y el estilo creativo del equipo responsable.

Por otra parte, hemos podido comprobar en primera persona las limitaciones derivadas de la falta de estudios de referencia que profundicen en la convergencia de campos propuesta, especialmente por la poca consideración a nivel académico e investigador que todavía sufre la LIJ, la fantasía literaria y el cine de animación.

Esperamos que el interés por el estudio científico y la investigación sobre la materia vayan aumentando en el futuro y pueda irse allanando camino para la entrada de estas producciones en las aulas, con el objetivo de construir audiencias activas y críticas, capaces de interpretar las producciones fílmicas y reflexionar sobre ellas.

A su vez, esto posibilitaría el incremento y la corrección de la presencia curricular del cine infantil y familiar, tanto en la educación primaria como en los planes docentes universitarios, y la actualización del trabajo en el aula en concordancia con la realidad que vive el alumnado en su día a día, consumidor asiduo y constante de las producciones audiovisuales cinematográficas $\mathrm{y}$ televisivas, cuyo poder socializador afecta directamente al desarrollo cognitivo, social y emocional del individuo.

\section{Referencias}

Ambròs, A. y Breu, R. (2007). Cine y educación. El cine en el aula de primaria y secundaria. Editorial Graó.

Ambròs-Pallarès, A. (2020). Cine, transmedia y educación: relatos en pantalla. Reire, 13(1), 1-18. http://doi. org/10.1344/reire2020.13.128644

Arendt, K., Rössler, P., Kalch, A. y Spitzner, F. (2010). Children's film in Europe: A literature review. Peter Lang.

Armenteros Gallardo, M. (2011). Efectos visuales y animación. En M. Armenteros (Dir.), Postproducción digital (pp. 70-104). Bubok. http://hdl.handle. net/10016/12928

Attebery, B. (1980). The fantasy tradition in American Literature. Indiana University Press.

Attebery, B. (1992). Strategies of fantasy. Indiana University Press.

Attebery, B. (2014). Stories about stories: Fantasy and the remaking of myth. Ofxord University Press.

Bardin, L. (1991). El análisis de contenido. Akal.

Bazalgette, C. y Staples, T. (1995). Unshrinking the kids: Children's cinema and the family film. En C. Bazalgette y D. Buckingham (Eds.), In front of the children: Screen entertainment and young audiences (pp. 92-108). British Film Institute.

Beckett, S. (2009). Crossover fiction: Global and historical perspectives. Routledge.

Brown, N. (2012). The Hollywood family film: A history, from Shirley Temple to Harry Potter. I.B. Tauris.

Brown, N. (2017). The Children's film (Short cuts). Columbia University Press.

Brown, N. (2019). Change and continuity in contemporary children's cinema. En C. Hermansson y J. Zepernick (Eds.), The Palgrave handbook of children's film and television (pp. 225-244). Palgrave Macmillan. https://doi.org/10.1007/978-3-030-17620-4_12

Brown, N. y Babington, B. (2015). Family films in global cinema: The world beyond Disney. I.B. Tauris.

Cáceres, P. (2003). Análisis cualitativo de contenido: una alternativa metodológica alcanzable. Psicoperspectivas: Revista de la Escuela de Psicología, 2(1), 53-82. https://www.psicoperspectivas.cl/index. $\mathrm{php} / \mathrm{psicoperspectivas/article/view/3}$

Cadavid, A. (2000). Adaptación e intertextualidad. Íkala, Revista de Lenguaje y Cultura, 5(1-2), 107-127. https://revistas.udea.edu.co/index.php/ikala/ article/view/8548

Camuñas García-Miguel, A. M. (2017). El cine en la escuela. Calanda. Revista didáctica de la acción educativa española en Francia, (12), 17-24. https://dialnet. unirioja.es/servlet/articulo?codigo $=6245448$

Cerrillo Torremocha, P. y Yubero, S. (2007). Qué leer y en qué momento. En P. Cerrillo y S. Yubero (Eds.), La formación de mediadores para la promoción de la lectura (pp. 285-292). Ediciones del CEPLI y Fundación SM.

Comisión Europea (2013). Screening literacy: Executive summary. https://op.europa.eu/ 
en / publication-detail / - / publication / cbc5f0fb-3a04-4b44-898b-8b61b0b1c520

Donald, S. H. y Seale, K. (2013). Children's film culture. En D. Lemish (Ed.), The Routledge international handbook of children, adolescents and media (pp. 95-102). Routledge.

Egoff, S. A. (1988). Worlds within: Children's fantasy from the Middle Ages to today. American Library Association.

Falconer, R. (2009). The crossover novel: Contemporary children's fiction and its readership. Routledge.

Falconer, R. (2010). Young adult fiction and the crossover phenomenon. En D. Rudd (Ed.), The Routledge companion to children's literature (pp. 87-99). Routledge.

Ferrés Prats, J. (2007). La competencia en comunicación audiovisual: dimensiones e indicadores. Comunicar. Revista Cientifica de Comunicación y Educación, 29, 100-107. https://doi.org/10.3916/C29-2007-14

Francescutti, P. (2019). La narración audiovisual como documento social e histórico: enfoques teóricos y métodos analíticos. EMPIRIA. Revista de Metodologia de Ciencias Sociales, (42), 137-161. https://doi. org/10.5944/empiria.42.2019.23255

Furtado, F. (1980). A construção do fantástico na narrativa. Livros Horizonte.

Gagliardi, L. (2020). ¿Literatura fantástica según quién? Diferentes aristas de un problema. Catalejos. Revista sobre lectura, formación de lectores y literatura para niños, 5(10), 16-41. https://fh.mdp.edu.ar/revistas/ index.php/catalejos/article/view/3976

Gamble, N. y Yates, S. (2008). Exploring Children's Literature. SAge Publications.

García Arias, T. (2020). Cine y educación: una propuesta didáctica. Making of: Cuadernos de Cine $y$ Educación, 150, 13-19. https://www.centrocp.com/ cine-y-educacion-una-propuesta-didactica/

Gates, P. S., Steffel, B. y Molson, F.-J. (2003). Fantasy literature for children and young Adults. Scarecrow Press.

González-Fernández, N., Ramírez-García, A. y SalcinesTalledo, I. (2018). Competencia mediática y necesidades de alfabetización audiovisual de docentes y familias españolas. Educación XX1, 21(2), 301321. https://doi.org/10.5944/educXX1.16384

G-Pedreira, R. (2020). A incidencia de reescrituras fílmicas na relación de nomeados e premiados dos principais galardóns internacionais a longametraxes animadas. Boletin Galego de Literatura, 56, 23-40. https://doi. org/10.15304/bgl.56.6776
Guichot Reina, V. y Álvarez Domínguez, P. (2002). Infancia y cine: algunas reflexiones sobre el papel que han de desempeñar la familia y la escuela. En M. del C. García Molina (Coord.), Familia, comunicación y educación (pp. 371-378). Diputación de Sevilla.

Held, J. (1985): Los niños y la literatura fantástica. Función y poder de lo imaginario. Paidós.

Hermansson, C. y Zepernick, J. (2019). Children's film and television: Contexts and new directions. En C. Hermansson y J. Zepernick (Eds.), The Palgrave handbook of children's film and television (pp. 1-33). Palgrave Macmillan. https://doi.org/10.1007\% 2F978-3-030-17620-4_1

Hernández López, S. B. (2015). Cinco etapas lectoras para favorecer los procesos de lectura. AZ. Revista de educación y cultura, 96, 38-49. https://www.academia. edu/21607831/Cinco_etapas_lectoras_para_favorecer_los_procesos_de_lectura

Hume, K. (1984). Fantasy and mimesis. Routledge.

Instituto de la Cinematografía y de las Artes Audiovisuales. (s. f.). Catálogo. Películas calificadas. http://www. culturaydeporte.gob.es/cultura/areas/cine/mc/catalogodecine/inicio.html

Internet Movie Database. (s. f.). https://www.imdb.com/

Irwin, W-R. (1976). The game of the impossible. A rethoric of fantasy. University of Illinois Press.

Jackson, R. (1986). Fantasy: literatura y subversión. Catálogos Editora.

Johansen, K-V. (2005). Quests and kingdoms: A grown-up's guide to children's fantasy. Sybertooth Inc.

Krämer, P. (2002). “The best Disney film never made”: Children's films and the family audience in American cinema since the 1960s. En S. Neale (Ed.), Genre And contemporary Hollywood (pp. 185-200). British Film Institute.

Krippendorff, K. (1990). Metodología de análisis de contenido. Teoría y práctica. Paidós Comunicación.

Lara, F., Ruíz, M. y Tarín, M. (Coords.). (2019). Cine y educación. Documento marco. Academia de las Artes y las Ciencias Cinematográficas de España. https:// www.academiadecine.com/educacion/

Levy, M. y Mendlesohn, F. (2016). Children's fantasy literature. An introduction. Cambridge University Press.

López Noguero, F. (2002). El análisis de contenido como método de investigación. Revista de Educación, (4), 167-179. http://rabida.uhu.es/dspace/ handle/10272/1912 
López Serrano, M. (2019). El cine como propuesta pedagógica en el alumnado del Grado de Maestro en Educación Primaria. El Futuro del Pasado, 10, 327-341. https://doi.org/10.14516/ fdp.2019.010.001.012

Manlove, C. N: (1975). Modern fantasy: Five studies. Cambridge University Press.

Manlove, C. N. (1983). The impulse of fantasy literature. The Macmillan Press. https://doi. org/10.1007/978-1-349-06383-3

Manlove, C. (2003). From Alice to Harry Potter. Cybereditions Corporation.

Marfil Carmona, R. (2008). Estrategias para la educación audiovisual. Cuadernos de Comunicación, 2, 91-107. https://www.researchgate.net/ publication/28272263_Estrategias_para_la_educacion_audiovisual

Martínez, J-M. (2010). ¿Subversión u oxímoron?: la literatura fantástica y la metafísica del objeto. RILCE, 26(2), 363-382. https://revistas.unav.edu/index. $\mathrm{php/rilce/article/view/4723/4072}$

Mayring, P. (2000). Qualitative content analysis. Forum: Qualitative Social Research, 1(2), art. 20. http:// nbn-resolving.de/urn:nbn:de:0114-fqs0002204

McCallum, R. (2018). Screen adaptations and the politics of childhood. Palgrave Macmillan. https://doi. org/10.1057/978-1-137-39541-2

Medina, A. (1957). Bibliografía selectiva sobre literatura infantil. Revista de Educación, (63), 25-29. http:// redined.mecd.gob.es/xmlui/handle/11162/82668

Mendlesohn, F. (2008). Rhetorics of fantasy. Wesleyan University Press.

Newton, M. (2006). Til I'm grown: Reading children's films; reading Walt Disney's The Jungle Book. En F.M. Collins y J. Ridgman (Eds.), Turning the page: Children's literature in performance and the media (pp. 17-38). Peter Lang.

Nikolajeva, M. (1988). The magic code. The use of magical patterns in fantasy for children. Almqvist \& Wiksell International.

Nikolajeva, M. (2012). The development of children's fantasy. En E. James y F. Mendlesohn (Eds.), The Cambridge companion to fantasy literature (pp. 5061). Cambridge University Press.

Núñez-Gómez, P., Cutillas-Navarro, M.-J. y ÁlvarezFlores, E.-P. (2020). Cine como herramienta de aprendizaje creativo en educación primaria. Es- tudios sobre Educación, 38, 233-251. https://doi. org/10.15581/004.38.233-251

Oliva Rota, M. (2006). Panorámica de la educación en comunicación audiovisual. Quaderns del CAC, (25), 29-40. https://www.cac.cat/sites/default/files/ migrate/quaderns_cac/Q25_ES.pdf

Ortega Carrillo, J. A. y Pérez García, A. (2013). El cine digital en la formación inicial del profesorado: una experiencia innovadora realizada en la Universidad de Granada. Educación XX1, 16(2), 297-320. 10.5944/educxx1.16.2.2644

Paik, K. (2007). To infinity and beyond! The story of Pixar Animation Studios. Chronicle Books.

Parry, B. (2013). Children, film and literacy. Palgrave Macmillan. https://doi.org/10.1057/9781137294333

Pérez Bowie, J. A. (2010). Sobre reescritura y nociones conexas. Un estado de la cuestión. En J. A. Pérez Bowie (Ed.), Reescrituras fílmicas. Nuevos territorios de la adaptación (pp. 21-43). Ediciones Universidad de Salamanca.

Pérez Millán, J. A. (2014). Cine, enseñanza y enseñanza del cine. Ediciones Morata.

Pérez Serrano, G. (1994). Investigación cualitativa. Retos e interrogantes I y II. La Muralla.

Piaget, J. (1933/2001). La representación del mundo en el niño. Morata.

Piaget, J. (1964/1991). Seis estudios de psicología. Labor.

Piñeiro-Naval, V. (2020). The content analysis methodology. Uses and applications in communication research on Spanish-speaking countries. Communication \& Society, 33(3),1-15. https://doi. org/10.15581/003.33.3.1-15

Pujante, D. (2016). Las inquisiciones de la literatura fantástica. El futuro del pasado, 7, 37-63. http://dx.doi. org/10.14516/fdp.2016.007.001.001

Ramos, A-M. y Navas, D. (2015). Narrativas juvenis: o fenómeno "crossover" nas literaturas portuguesa e brasileira. Elos. Revista de literatura infantil e xuvenil, (2), 233-256. http://dx.doi.org/10.15304/ elos.2.2745

Richard, S. (2009). El análisis de contenido en la investigación sobre didáctica de la literatura. Enunciación, 14(1), 145-164. https://doi. org/10.14483/22486798.3284

Rodríguez Rosell, M. y Melgarejo Moreno, I. (2010). Cine infantil: aproximación a una definición. Doxa Comunicación: revista interdisciplinar de estudios de 
comunicación y ciencias sociales, (10), 167-181. http://hdl.handle.net/10637/5882

Sachiko Cecire, M. (2019). The rise of children's literature in the twentieth century. The University of Minnesota Press.

Shaw, B. (2010). The animal fable in science fiction and fantasy. McFarland.

Stam, R. (2000). Beyond fidelity: The dialogics of adaptation. En J. Naremore. (Ed.), Film adaptation. Rutgers University Press.

Todorov, T. (1970/1994). Introducción a la literatura fantástica. Ediciones Coyoacán.

Tolkien, J. R. R. (1983). On fairy stories. En C. Tolkien (Ed.), The monsters and the critics and other essays (pp. 109-161). George Allen and Unwin.
Vicent Martín, L. M (2016). El cine en la infancia: un medio educativo y transmisor de valores. Educación y Futuro Digital, (12), 109-119. https://redined. mecd.gob.es/xmlui/handle/11162/120819.

Viñolo Locubiche, S. y Duran-Castells, J. (2013). Entre lo siniestro y lo subversivo. Categorías estéticas del cine de animación híbrido. Archivos de la Filmoteca, (72), 37-49. http://www.archivosdelafilmoteca.com/index.php/archivos/article/view/488

Wells, P. (2007). Fundamentos de la animación. Parramón.

Yubero, S. (2005). Socialización y aprendizaje social. En D. Páez Rovira, I. Fernández Sedano, S. Ubillos Landa y E. Mercedes Zubieta (Coords.), Psicología social, cultura y educación (pp. 819-844). Pearson. https:// www.ehu.eus/documents/1463215/1504276/ Capitulo+XXIV.pdf 


\section{Anexo. Muestra de películas y libros estudiados}

A: para todos los públicos

+7: no recomendada para menores de 7 años

i: especialmente recomendada para la infancia

\begin{tabular}{|c|c|c|c|c|c|}
\hline $\begin{array}{l}\text { Estreno España } \\
\text { (mes/año) }\end{array}$ & Hipertexto & Director & Estética & Hipotexto & Autor \\
\hline $11 / 1996$ & $\begin{array}{l}\text { James and the Giant } \\
\text { Peach (1996)(A) }\end{array}$ & Henry Selick & Mixta & $\begin{array}{l}\text { James and the Giant } \\
\text { Peach(1961) }\end{array}$ & Roald Dahl \\
\hline 02/1997 & $\begin{array}{l}\text { l01 Dalmatians(1996) } \\
\text { (A) }\end{array}$ & Stephen Herek & Realista & $\begin{array}{l}\text { The Hundred and One } \\
\text { Dalmatians (1956) }\end{array}$ & Dodie Smith \\
\hline 09/1998 & Dr. Dolittle (1998) (A) & Betty Thomas & Realista & $\begin{array}{l}\text { Serie Doctor Dolittle } \\
(1920-1952)\end{array}$ & Hugh Lofting \\
\hline 12/1999 & Iron Giant(1999) (A) & Brad Bird & Animada & The Iron Man (1968) & Ted Hughes \\
\hline $06 / 2000$ & Stuart Little (1999) (A) & Rob Minkoff & Realista & Stuart Little (1945) & E. B. White \\
\hline $11 / 2000$ & $\begin{array}{l}\text { How the Grinch Stole } \\
\text { Christmas (2000) (A) }\end{array}$ & Ron Howard & Realista & $\begin{array}{l}\text { How the Grinch Stole } \\
\text { Christmas!(1957) }\end{array}$ & Dr. Seuss \\
\hline $12 / 2000$ & $\begin{array}{l}\text { Der kleine Vampir [El } \\
\text { pequeño vampiro] }(2000) \\
\text { (A) }\end{array}$ & Uli Edel & Realista & $\begin{array}{l}\text { Der kleine Vampir [El } \\
\text { pequeño vampiro](1979) }\end{array}$ & $\begin{array}{l}\text { Angela } \\
\text { Sommer-Bodenburg }\end{array}$ \\
\hline $06 / 2001$ & Shrek(2001)(A) & $\begin{array}{l}\text { Andrew Adamson y } \\
\text { Vicky Jenson }\end{array}$ & Animada & Shrek!(1990) & William Steig \\
\hline 07/2001 & $\begin{array}{l}\text { El bosque animado, } \\
\text { sentirás su magia (2001) } \\
\text { (A) }\end{array}$ & $\begin{array}{l}\text { Ángel de la Cruz y } \\
\text { Manolo Gómez }\end{array}$ & Animada & $\begin{array}{l}\text { El bosque animado } \\
\text { (1943) }\end{array}$ & $\begin{array}{l}\text { Wenceslao Fernández } \\
\text { Flórez }\end{array}$ \\
\hline $11 / 2001$ & $\begin{array}{l}\text { Harry Potter and the } \\
\text { Philosopher's Stone } \\
\text { (2001) (A) }\end{array}$ & Chris Columbus & Realista & $\begin{array}{l}\text { Harry Potter and the } \\
\text { Philosopher's Stone } \\
\text { (1997) }\end{array}$ & J. K. Rowling \\
\hline $03 / 2004$ & Peter Pan (2003) (A) & P. J. Hogan & Realista & Peter and Wendy (1911) & J. M. Barrie \\
\hline $07 / 2004$ & $\begin{array}{l}\text { P3K: Pinocho } 3000 \\
\text { (2004) (A) }\end{array}$ & Daniel Robichaud & Animada & $\begin{array}{l}\text { Le avventure di Pinoc- } \\
\text { chio (1881) }\end{array}$ & Carlo Collodi \\
\hline $12 / 2004$ & Polar Express (2004) (A) & Robert Zemeckis & Animada & The Polar Express (1985) & Chris Van Allsburg \\
\hline 08/2005 & $\begin{array}{l}\text { Charlie and the Chocola- } \\
\text { te Factory (2005) (A) }\end{array}$ & Tim Burton & Realista & $\begin{array}{l}\text { Charlie and the Chocola- } \\
\text { te Factory (1964) }\end{array}$ & Roald Dahl \\
\hline $12 / 2005$ & $\begin{array}{l}\text { The Chronicles of Narnia: } \\
\text { The Lion, the Witch and } \\
\text { the Wardrobe (2005) } \\
(+7)\end{array}$ & Andrew Adamson & Realista & $\begin{array}{l}\text { The Lion, the Witch and } \\
\text { the Wardrobe (1950) }\end{array}$ & C. S. Lewis \\
\hline $03 / 2006$ & $\begin{array}{l}\text { El Castillo ambulante } \\
(2004)(+7)\end{array}$ & Hayao Miyazaki & Animada & $\begin{array}{l}\text { Howl's Moving Castle } \\
\text { (1986) }\end{array}$ & Diana Wynne Jones \\
\hline
\end{tabular}




\section{Anexo. Muestra de películas y libros estudiados (Cont.)}

\begin{tabular}{|c|c|c|c|c|c|}
\hline $\begin{array}{l}\text { Estreno España } \\
\text { (mes/año) }\end{array}$ & Hipertexto & Director & Estética & Hipotexto & Autor \\
\hline $04 / 2006$ & Nanny McPhee (2005) (A) & Kirk Jones & Realista & $\begin{array}{l}\text { Nurse Matilda(1964), } \\
\text { Nurse Matilda Goes } \\
\text { to Town(1967), Nurse } \\
\text { Matilda Goes to Hospital } \\
\text { (1974) }\end{array}$ & Christianna Brand \\
\hline 09/2006 & Ant Bully (2006) (A) & John A. Davis & Animada & The Ant Bully (1999) & John Nickle \\
\hline $12 / 2006$ & Eragon $(2006)(A)$ & Stefen Fangmeier & Realista & Eragon(2002) & Christopher Paolini \\
\hline $12 / 2006$ & $\begin{array}{l}\text { Arthur et les Minimoys } \\
(2006)(A)\end{array}$ & Luc Besson & Mixta & $\begin{array}{l}\text { Arthur et les Minimoys } \\
\text { (2002) y Arthur et la Cité } \\
\text { interdite (2003) }\end{array}$ & Luc Besson \\
\hline $12 / 2007$ & $\begin{array}{l}\text { Cuentos de Terramar } \\
(2006)(+7)\end{array}$ & Gorō Miyazaki & Animada & $\begin{array}{l}\text { The Farthest Shore } \\
\text { (1972) y Tehanu (1990) }\end{array}$ & Ursula K. Le Guin \\
\hline $12 / 2007$ & $\begin{array}{l}\text { The Golden Compass } \\
(2007)(+7)\end{array}$ & Chris Weitz & Realista & Northern Lights (1995) & Philip Pullman \\
\hline $03 / 2008$ & $\begin{array}{l}\text { Horton Hears a Who! } \\
\text { (2008) (Ai) }\end{array}$ & $\begin{array}{l}\text { Jimmy Hayward y } \\
\text { Steve Martino }\end{array}$ & Animada & $\begin{array}{l}\text { Horton Hears a Who! } \\
\text { (1954) }\end{array}$ & Dr. Seuss \\
\hline $03 / 2008$ & $\begin{array}{l}\text { The Spiderwick Chroni- } \\
\text { cles }(2008)(+7)\end{array}$ & Mark Waters & Realista & $\begin{array}{l}\text { The Spiderwick Chroni- } \\
\text { cles (2003, 2003, 2004, } \\
\text { 2004) }\end{array}$ & $\begin{array}{l}\text { Tony DiTerlizzi y Holly } \\
\text { Black }\end{array}$ \\
\hline $03 / 2008$ & $\begin{array}{l}\text { The Water Horse (2007) } \\
\text { (A) }\end{array}$ & Jay Russell & Realista & The Water Horse (1990) & Dick King-Smith \\
\hline 04/2009 & $\begin{array}{l}\text { Ponyo en el acantilado } \\
\text { (2008) (Ai) }\end{array}$ & Hayao Miyazaki & Animada & Den lille Havfrue (1837) & $\begin{array}{l}\text { Hans Christian } \\
\text { Andersen }\end{array}$ \\
\hline $06 / 2009$ & Inkheart $(2008)(+7)$ & Iain Softley & Realista & Inkheart(2003) & Cornelia Funke \\
\hline 06/2009 & Coraline $(2009)(+7)$ & Henry Selick & Animada & Coraline (2002) & Neil Gaiman \\
\hline 06/2009 & $\begin{array}{l}\text { Hexe Lilli: Der Drache } \\
\text { und das magische Buch } \\
\text { [Kika Superbruja y el } \\
\text { libro de hechizos] (2009) } \\
\text { (A) }\end{array}$ & Stefan Ruzowitzky & Realista & $\begin{array}{l}\text { Hexe Lilli und das Buch } \\
\text { des Drachen (2008) }\end{array}$ & $\begin{array}{l}\text { Ludger Jochmann } \\
\text { (KNISTER) }\end{array}$ \\
\hline $11 / 2009$ & $\begin{array}{l}\text { A Christmas Carol(2009) } \\
(+7)\end{array}$ & Robert Zemeckis & Animada & A Christmas Carol(1843) & Charles Dickens \\
\hline $12 / 2009$ & $\begin{array}{l}\text { Where the Wild Things } \\
\text { Are (2009) (A) }\end{array}$ & Spike Jonze & Realista & $\begin{array}{l}\text { Where the Wild Things } \\
\text { Are (1963) }\end{array}$ & Maurice Sendak \\
\hline $12 / 2009$ & $\begin{array}{l}\text { Cloudy with a Chance of } \\
\text { Meatballs (2009) (A) }\end{array}$ & $\begin{array}{l}\text { Phil Lord y Chris- } \\
\text { topher Miller }\end{array}$ & Animada & $\begin{array}{l}\text { Cloudy with a Chance of } \\
\text { Meatballs (1978) }\end{array}$ & Judi Barrett \\
\hline $02 / 2010$ & $\begin{array}{l}\text { The Princess and the } \\
\text { Frog (2009) (A) }\end{array}$ & $\begin{array}{l}\text { Ron Clements y John } \\
\text { Musker }\end{array}$ & Animada & $\begin{array}{l}\text { Der Froschkönig oder } \\
\text { der eiserne Heinrich [El } \\
\text { príncipe rana](1812) y } \\
\text { The Frog Princess (2002) }\end{array}$ & $\begin{array}{l}\text { Hermanos Grimm y } \\
\text { E. D. Baker }\end{array}$ \\
\hline
\end{tabular}




\section{Anexo. Muestra de películas y libros estudiados (Cont.)}

\begin{tabular}{|c|c|c|c|c|c|}
\hline $\begin{array}{l}\text { Estreno España } \\
\text { (mes/año) }\end{array}$ & Hipertexto & Director & Estética & Hipotexto & Autor \\
\hline $02 / 2010$ & $\begin{array}{l}\text { Percy Jackson \& the } \\
\text { Olympians: The Light- } \\
\text { ning Thief }(2010)(+7)\end{array}$ & Chris Columbus & Realista & $\begin{array}{l}\text { The Lightning Thief } \\
\text { (2005) }\end{array}$ & Rick Riordan \\
\hline $03 / 2010$ & $\begin{array}{l}\text { How To Train Your } \\
\text { Dragon (2010) (7i) }\end{array}$ & $\begin{array}{l}\text { Chris Sanders y Dean } \\
\text { DeBlois }\end{array}$ & Animada & $\begin{array}{l}\text { Serie How to Train Your } \\
\text { Dragon (2003-2015) }\end{array}$ & Cressida Cowell \\
\hline $04 / 2010$ & $\begin{array}{l}\text { Fantastic Mr. Fox (2009) } \\
\text { (A) }\end{array}$ & Wes Anderson & Animada & Fantastic Mr. Fox (1970) & Roald Dahl \\
\hline $04 / 2010$ & $\begin{array}{l}\text { Alice in Wonderland } \\
(2010)(+7)\end{array}$ & Tim Burton & Realista & $\begin{array}{l}\text { Alice in Wonderland } \\
\text { (1865) }\end{array}$ & Lewis Carroll \\
\hline $10 / 2010$ & $\begin{array}{l}\text { Legend of The Guar- } \\
\text { dians: The Owls of } \\
\text { Ga'hoole (2010) (Ai) }\end{array}$ & Zack Snyder & Animada & $\begin{array}{l}\text { Guardians of Ga'Hoole: } \\
\text { The Capture (2003), } \\
\text { The Journey (2003), } \\
\text { The Rescue (2004) }\end{array}$ & Kathryn Lasky \\
\hline 03/2011 & $\begin{array}{l}\text { Mars Needs Moms (2011) } \\
\text { (A) }\end{array}$ & Simon Wells & Animada & $\begin{array}{l}\text { Mars Needs Moms! } \\
\text { (2007) }\end{array}$ & Berkeley Breathed \\
\hline $04 / 2011$ & $\begin{array}{l}\text { Winnie the Pooh (2011) } \\
\text { (Ai) }\end{array}$ & $\begin{array}{l}\text { Stephen J. Anderson y } \\
\text { Don Hall }\end{array}$ & Animada & Winnie the Pooh (1926) & A. A. Milne \\
\hline 09/2011 & $\begin{array}{l}\text { Arrietty y el mundo de } \\
\text { los diminutos (2010) (Ai) }\end{array}$ & Hiromasa Yonebayashi & Animada & The Borrowers (1952) & Mary Norton \\
\hline 09/2011 & $\begin{array}{l}\text { Konferenz der Tiere [Ani- } \\
\text { mals United] (2010) (Ai) }\end{array}$ & $\begin{array}{l}\text { Reinhard Klooss y } \\
\text { Holger Tappe }\end{array}$ & Animada & $\begin{array}{l}\text { Die Konferenz der Tiere } \\
\text { [La conferencia de los } \\
\text { animales] (1949) }\end{array}$ & Erich Kästner \\
\hline $12 / 2011$ & $\begin{array}{l}\text { The Nutcracker in 3D } \\
(2010)(\mathrm{A})\end{array}$ & Andrey Konchalovsky & Realista & $\begin{array}{l}\text { Nussknacker und Mause- } \\
\text { könig (1816) }\end{array}$ & E. T. A. Hoffmann \\
\hline 03/2012 & The Lorax (2013) (Ai) & $\begin{array}{l}\text { Chris Renaud y Kyle } \\
\text { Balda }\end{array}$ & Animada & The Lorax (1971) & Dr. Seuss \\
\hline $11 / 2012$ & $\begin{array}{l}\text { Rise of the Guardians } \\
\text { (2013) (Ai) }\end{array}$ & Peter Ramsey & Animada & $\begin{array}{l}\text { The Guardians of Child- } \\
\text { hood series (2011, 2011, } \\
2012,2012,2012,2013 \text {, } \\
2015,2018)\end{array}$ & William Joyce \\
\hline $12 / 2012$ & $\begin{array}{l}\text { The Hobbit: An Unexpec- } \\
\text { ted Journey }(2013)(+7)\end{array}$ & Peter Jackson & Realista & $\begin{array}{l}\text { The Hobbit, or There and } \\
\text { Back Again (1982) }\end{array}$ & J. R. R. Tolkien \\
\hline $03 / 2013$ & $\begin{array}{l}\text { Oz the Great and Power- } \\
\text { ful }(2013)(+7)\end{array}$ & Sam Raimi & Realista & Oz series $(1900-1920)$ & L. Frank Baum \\
\hline $08 / 2013$ & $\operatorname{Epic}(2013)(\mathrm{A})$ & Chris Wedge & Animada & $\begin{array}{l}\text { The Leaf Men and the } \\
\text { Brave Good Bugs (1996) }\end{array}$ & William Joyce \\
\hline $11 / 2013$ & Frozen $(2013)(\mathrm{A})$ & $\begin{array}{l}\text { Chris Buck y Jennifer } \\
\text { Lee }\end{array}$ & Animada & The Snow Queen (1845) & $\begin{array}{l}\text { Hans Christian } \\
\text { Andersen }\end{array}$ \\
\hline $\begin{array}{l}\text { Estreno España } \\
\text { (mes/año) }\end{array}$ & Hipertexto & Director & Estética & Hipotexto & Autor \\
\hline
\end{tabular}




\section{Anexo. Muestra de películas y libros estudiados (Cont.)}

\begin{tabular}{|c|c|c|c|c|c|}
\hline 09/2014 & $\begin{array}{l}\text { Die Biene Maja-Der } \\
\text { Kinofilm [La abeja Maya: } \\
\text { la película] (2014) (Ai) }\end{array}$ & $\begin{array}{l}\text { Stéphane Aubier } \\
\text { Vincent Pata y Benja- } \\
\text { min Renner } \\
\text { Alexs Stadermann }\end{array}$ & Animada & $\begin{array}{l}\text { Die Biene Maja und } \\
\text { ihre Abentever [Las } \\
\text { aventuras de la abeja } \\
\text { Maya](1912) }\end{array}$ & Waldemar Bonsels \\
\hline $10 / 2014$ & The Boxtrolls (2014) (A) & $\begin{array}{l}\text { Graham Annable y } \\
\text { Anthony Stacchi }\end{array}$ & Animada & Here Be Monsters!(2005) & Alan Snow \\
\hline $01 / 2015$ & Paddington (2014) (A) & Paul King & Realista & $\begin{array}{l}\text { Serie Paddington Bear } \\
(1958-2018)\end{array}$ & Michael Bond \\
\hline $03 / 2015$ & Home (2015) (A) & Tim Johnson & Animada & $\begin{array}{l}\text { The True Meaning of } \\
\text { Smekday (2007) }\end{array}$ & Adam Rex \\
\hline $12 / 2015$ & $\operatorname{Pan}(2015)(+7)$ & Joe Wright & Realista & Peter and Wendy (1911) & J. M. Barrie \\
\hline $03 / 2016$ & $\begin{array}{l}\text { El recuerdo de Marnie } \\
(2014)(+7)\end{array}$ & $\begin{array}{l}\text { James Simone y Hiro- } \\
\text { masa Yonebayashi }\end{array}$ & Animada & $\begin{array}{l}\text { When Marnie Was There } \\
\text { (1967) }\end{array}$ & $\begin{array}{l}\text { Joan Mary Gale } \\
\text { Robinson }\end{array}$ \\
\hline $04 / 2016$ & $\begin{array}{l}\text { The Jungle Book (2016) } \\
\text { (Ai) }\end{array}$ & Jon Favreau & Realista & $\begin{array}{l}\text { The Jungle Book (1894)y } \\
\text { The Second Jungle Book } \\
\text { (1895) }\end{array}$ & Rudyard Kipling \\
\hline 07/2016 & The BFG(2016)(Ai) & Steven Spielberg & Realista & The $B F G(1982)$ & Roald Dahl \\
\hline 09/2016 & Le Petit Prince (2015) (Ai) & Mark Osborne & Animada & Le Petit Prince (1943) & $\begin{array}{l}\text { Antoine de } \\
\text { Saint-Exupéry }\end{array}$ \\
\hline 09/2016 & $\begin{array}{l}\text { Miss Peregrine's Home } \\
\text { for Peculiar Children } \\
(2016)(+7)\end{array}$ & Tim Burton & Realista & $\begin{array}{l}\text { Miss Peregrine's Home } \\
\text { for Peculiar Children } \\
(2011)\end{array}$ & Ransom Riggs \\
\hline 03/2017 & $\begin{array}{l}\text { Beauty and the Beast } \\
\text { (2017) (Ai) }\end{array}$ & Bill Condon & Realista & La Belle et la Bête (1756) & $\begin{array}{l}\text { Jeanne Marie Leprince } \\
\text { de Beaumont }\end{array}$ \\
\hline $06 / 2017$ & $\begin{array}{l}\text { Captain Underpants: The } \\
\text { First Epic Movie (2017) } \\
\text { (Ai) }\end{array}$ & David Soren & Animada & $\begin{array}{l}\text { The Adventures of Cap- } \\
\text { tain Underpants (1997) }\end{array}$ & Dav Pilkey \\
\hline 06/2017 & $\begin{array}{l}\text { Nur eta Herensugearen } \\
\text { Tenplua [Nur y el templo } \\
\text { del dragón] (2017) (Ai) }\end{array}$ & $\begin{array}{l}\text { Juan Bautista } \\
\text { Berasategi }\end{array}$ & Animada & $\begin{array}{l}\text { Nur Tenplua eta Heren- } \\
\text { sugearen (2009) }\end{array}$ & Toti Martínez de Lezea \\
\hline $10 / 2017$ & $\begin{array}{l}\text { The Little Vampire 3D } \\
\text { (2017) (Ai) }\end{array}$ & $\begin{array}{l}\text { Richard Claus y } \\
\text { Karsten Kiilerich }\end{array}$ & Animada & $\begin{array}{l}\text { Der kleine Vampir [EI } \\
\text { pequeño vampiro](1979) }\end{array}$ & $\begin{array}{l}\text { Angela } \\
\text { Sommer-Bodenburg }\end{array}$ \\
\hline $\begin{array}{l}\text { Estreno España } \\
\text { (mes/año) }\end{array}$ & Hipertexto & Director & Estética & Hipotexto & Autor \\
\hline
\end{tabular}




\section{Anexo. Muestra de películas y libros estudiados (Cont.)}

\begin{tabular}{|c|c|c|c|c|c|}
\hline $11 / 2017$ & $\begin{array}{l}\text { Dyrene i Hakkebakkes- } \\
\text { kogen [El bosque de } \\
\text { Haquivaqui](2016) (Ai) }\end{array}$ & Rasmus A. Sivertsen & Animada & $\begin{array}{l}\text { Klatremus og de andre } \\
\text { dyrene i Hakkebakkes- } \\
\text { kogen (1953) }\end{array}$ & Thorbjorn Egner \\
\hline $12 / 2017$ & Ferdinand(2017) (Ai) & Carlos Saldanha & Animada & $\begin{array}{l}\text { The Story of Ferdinand } \\
\text { (1936) }\end{array}$ & $\begin{array}{l}\text { Munro Leaf y Robert } \\
\text { Lawson }\end{array}$ \\
\hline $03 / 2018$ & $\begin{array}{l}\text { A Wrinkle in Time (2018) } \\
(+7)\end{array}$ & Ava DuVernay & Realista & A Wrinkle in Time (1962) & Madeleine l'Engle \\
\hline $03 / 2018$ & Peter Rabbit(2018) (Ai) & Will Gluck & Realista & $\begin{array}{l}\text { The Tale of Peter Rabbit } \\
\text { (1902) }\end{array}$ & Beatrix Potter \\
\hline 09/2018 & Ana y Bruno $(2017)(+7)$ & Carlos Carrera & Animada & Ana (2018) & Daniel Emil \\
\hline 10/2018 & $\begin{array}{l}\text { Die kleine Hexe [La } \\
\text { pequeña brujita](2018) } \\
\text { (Ai) }\end{array}$ & Mike Schaerer & Realista & $\begin{array}{l}\text { Die kleine Hexe [La } \\
\text { pequeña Bruja](1957) }\end{array}$ & Otfried Preußler \\
\hline $10 / 2018$ & $\begin{array}{l}\text { The House with a Clock } \\
\text { in lts Walls }(2018)(+7)\end{array}$ & Eli Roth & Realista & $\begin{array}{l}\text { The House with a Clock } \\
\text { in lts Walls (1973) }\end{array}$ & John Bellairs \\
\hline $10 / 2018$ & $\begin{array}{l}\text { Christopher Robin (2018) } \\
\text { (Ai) }\end{array}$ & Marc Forster & Realista & $\begin{array}{l}\text { Winnie the Pooh(1926), } \\
\text { The House at Pooh } \\
\text { Corner }(1928)\end{array}$ & A. A. Milne \\
\hline $10 / 2018$ & $\begin{array}{l}\text { The Nutcracker and the } \\
\text { Four Realms (2018) (Ai) }\end{array}$ & $\begin{array}{l}\text { Lasse Hallström y Joe } \\
\text { Johnston }\end{array}$ & Realista & $\begin{array}{l}\text { Nussknacker und Mause- } \\
\text { könig(1816) }\end{array}$ & E. T. A. Hoffmann \\
\hline $11 / 2018$ & The Grinch (2018) (Ai) & $\begin{array}{l}\text { Yarrow Cheney y Scott } \\
\text { Mosier }\end{array}$ & Animada & $\begin{array}{l}\text { How the Grinch Stole } \\
\text { Christmas!(1957) }\end{array}$ & Dr. Seuss \\
\hline $03 / 2019$ & Dumbo (2019) (Ai) & Tim Burton & Realista & $\begin{array}{l}\text { Dumbo, the Flying } \\
\text { Elephant(1939) }\end{array}$ & $\begin{array}{l}\text { Helen Aberson y } \\
\text { Harold Pearl }\end{array}$ \\
\hline
\end{tabular}

Cómo citar este artículo: Pedreira, R. G. y Silva, S. R. da (2022). Las técnicas de animación y la estética de la imagen en la reescritura fílmica de la literatura fantástica infantil y juvenil difundida en España (1996-2019). Íkala, Revista de Lenguaje y Cultura, 27(1), 174-197. https://doi.org/10.17533/udea. ikala.v27n1a09 